\title{
El municipio turístico de Andalucía: claves sustantivas de su nueva regulación ${ }^{1}$
}

\author{
The tourist municipality of Andalucía: substantive keys of its new \\ regulation
}

\author{
María del Carmen Núñez Lozano \\ Universidad de Huelva \\ maria.lozano@dpub.uhu.es
}

\section{NOTA BIOGRÁFICA}

Doctora en Derecho por la Universidad de Sevilla. Catedrática de Derecho Administrativo de la Universidad de Huelva. Sus líneas de investigación se centran en las técnicas de intervención administrativa (en especial, régimen de actividades comunicadas), sectores de actividad (en especial, ordenación de los seguros privados y sanidad) y protección del medioambiente (en especial, régimen jurídico de las costas).

\section{RESUMEN}

Este trabajo estudia los aspectos sustantivos de la nueva regulación de Andalucía sobre los municipios turísticos. El análisis jurídico del Decreto 72/2017 permite concluir que la calidad es el principal objetivo de la norma; que se acentúa la consideración de la declaración de Municipio Turístico de Andalucía como un punto de partida y no una meta de llegada; y que la finalidad de este régimen no es compensar los mayores gastos que supone la afluencia de visitantes sino la de mantener y elevar el atractivo turístico del municipio.

\section{PALABRAS CLAVE}

Financiación municipal; turismo.

\begin{abstract}
This paper studies the substantive aspects of the new andalusian regulation on tourist municipalities. The legal analysis of Decree 72/2017 allows us to conclude that quality is its main objective; that the declaration of «Tourist Municipality of Andalusia» is accentuated as a starting point and not as an arrival goal; and that the purpose of this regime is not to compensate the greater expenses that visitors affluence supposes but to maintain and elevate the tourist attraction of the municipality.
\end{abstract}

\section{KEYWORDS}

Municipal financing, tourism.

\section{SUMARIO}

I. INTRODUCCIÓN. II. LAS FINALIDADES QUE PERSIGUE LA REGULACIÓN SOBRE EL MUNICIPIO TURÍSTICO. III. PREMISA Y REQUISITOS SUSTANTIVOS PARA ALCANZAR LA CONDICIÓN DE MUNICIPIO TURÍSITICO. III.1. PREMISA PARA ALCANZAR LA CONDICIÓN DE MUNICIPIO TURÍSTICO:

\footnotetext{
1 Este estudio se ha realizado en el marco del Centro de Investigación en Patrimonio Histórico, Cultural y Natural y del grupo de investigación "Derecho, Economía y Sociedad" (SEJ-397). Universidad de Huelva.
} 
EL NÚMERO DE HABITANTES. III.2. LOS REQUISITOS SUSTANTIVOS PARA ALCANZAR LA CONDICIÓN DE MUNICIPIO TURÍSTICO. III.2.1. La población turística asistida. III.2.2. La oferta turística. III.2.3. El plan municipal de calidad turística. III.2.4. Los elementos de valoración. IV. LOS EFECTOS DE LA DECLARACIÓN DE MUNICIPIO TURÍSITICO DE ANDALUCÍA. IV.1. LAS OBLIGACIONES DE LA ADMINISTRACIÓN DE LA JUNTA DE ANDALUCÍA. IV.2. LAS OBLIGACIONES DE LOS MUNICIPIOS TURÍSTICOS DE ANDALUCÍA. IV.3. LOS CONVENIOS DE COLABORACIÓN. IV.4. OTRAS FORMAS DE COLABORACIÓN INTERADMINISTRATIVA. V. CONCLUSIONES. VI. BIBLIOGRAFÍA.

\section{INTRODUCCIÓN}

La Comunidad Autónoma de Andalucía contempló el municipio turístico (MT) en su primera ley de ordenación y promoción del turismo, la Ley 12/1999, de 15 de diciembre, del Turismo (L99). Fue desarrollada por el Decreto 158/2002, de 28 de mayo, de Municipio Turístico (D/2002), modificado por el Decreto 70/2006, de 21 de marzo (D/2006) ${ }^{2}$. Hoy, es el Decreto 72/2017, de 13 de junio, de Municipio Turístico de Andalucía ${ }^{3}$ (DMTA) el que desarrolla los artículos 19 y 20 de la Ley 13/2011, de 23 de diciembre, del Turismo de Andalucía (LTA), otorgando carta de naturaleza a la concreta denominación «Municipio Turístico de Andalucía» ${ }^{4}$ (MTA).

Aun cuando las líneas maestras del MT se han mantenido ${ }^{5}$, la Ley y el Decreto han introducido novedades de interés. En este estudio nos ocuparemos de los requisitos para alcanzar la condición de MTA y de los efectos de la declaración, que son los dos aspectos esenciales de la regulación, soslayando el procedimiento de declaración y la revocación de la misma, sin perjuicio de puntuales referencias. Con carácter previo se expondrán unas breves consideraciones sobre las finalidades que persigue la regulación, útiles para enmarcar el análisis.

\section{LAS FINALIDADES QUE PERSIGUE LA REGULACIÓN SOBRE EL MUNICIPIO TURÍSTICO}

Conviene recordar que el MT es una figura prevista en la legislación de régimen local o turística de distintas Comunidades Autónomas, con un claro perfil orientado a las singularidades de aquellos municipios que, debido a su atractivo turístico, han de atender a una población compuesta no solo por los vecinos sino, también, por quienes lo visitan en régimen de estancia temporal. Como ha señalado la doctrina (CORNO CAPARRÓS $^{6}$ ), la afluencia de visitantes ${ }^{7}$ les obliga a prestar unos servicios cuantitativa y cualitativamente distintos de los que, con arreglo a la población de derecho, les correspondería, de manera irregular en el tiempo cuando la afluencia es, como generalmente sucede, estacional ${ }^{8}$. De ahí que sea necesario acudir a fórmulas encaminadas a la obtención de los recursos precisos para poder prestar los diferentes servicios, para poder cubrir «el incremento de sus necesidades financieras ${ }^{9}$, una de las cuales es la del «municipio tu-

2 Por acuerdo del Consejo de Gobierno, han sido declarados municipios turísticos bajo este régimen: Benalmádena (acuerdo de 21 de octubre de 2003), Santiponce (acuerdo de 9 de diciembre de 2003), Ronda (acuerdo de 9 de marzo de 2004), Cazorla, Nerja y Roquetas de Mar (acuerdos de 15 de marzo de 2005), Aracena, Chiclana de la Frontera, Conil de la Frontera, Tarifa y Torremolinos (acuerdos de 9 de mayo de 2006), Chipiona y Fuengirola (acuerdos de 25 de julio de 2006), Rota (acuerdo de 27 de marzo de 2007 ), Almonte (acuerdo de 24 de marzo de 2009), Almuñécar (acuerdo de 5 de abril de 2011), Baeza (acuerdo de 16 de enero de 2017) y Punta Umbría (acuerdo de 19 de septiembre de 2017).

3 BOJA número 119, de 23 de junio de 2017, sección "Otras disposiciones"; en el BOJA 121, de 27 de junio de 2017 , se procedió a la publicación íntegra del Decreto mediante una corrección de erratas, si bien en la sección "Disposiciones generales".

4 Bajo el régimen anterior, la expresión «municipio turístico» se ha utilizado en regulaciones diferentes con distinto significado y alcance. Así, el artículo 5.5 del Decreto 353/2003, de 16 de diciembre, por el que se establecen la planificación farmacéutica y los procedimientos de autorización relativos a oficinas de farmacia, consideraba «municipios turísticos aquellos en los que las plazas de alojamientos turísticos superen el $5 \%$ de la cifra de población según el Padrón Municipal vigente».

5 Acaso por ello, el preámbulo de la LTA no menciona la figura del MT, a diferencia del de la L99, que le dedica varios párrafos. Claramente, el MT no supone en 2011 ninguna novedad.

6 1984: 427 .

7 Utilizaré la palabra «visitante» sin la precisión que aportó al concepto el artículo 2.2 D/2002, que consideró que lo era «la persona que se desplaza a un lugar distinto al de su entorno habitual sin alojarse en ningún establecimiento turístico, no siendo el motivo principal del viaje el ejercicio de una actividad remunerada en el lugar visitado». La regulación actual prescinde de este concepto.

8 Subrayan LASARTE ÁLVAREZ y ADAME MARTÍN que la estacionalidad agrava el problema (2005: 449 y 450)

9 LASARTE ÁLVAREZ y ADAME MARTÍN, 2005: 436. Los autores sintetizan la cuestión en los términos que, por su claridad y brevedad, se reproducen a continuación: «[y] el problema consiste en que el sistema actual de financiación local se apoya básicamente en las participaciones en tributos estatales, para cuya cuantificación el dato principal es la población de derecho [...]; y, en segundo lugar, se fundamenta en los tributos propios, especialmente en los impuestos municipales, cuya carga puede sólo modularse igualmente en función de tal población de derecho» (2005: 447). 
rístico». Ello no obstante, y como también se ha advertido (FERNÁNDEZ RAMOS ${ }^{10}$ ), el perfil del MT «como municipio de gran afluencia turística» se ha "desdibujado» en la legislación turística con la introducción de rasgos característicos de «municipio de interés turístico».

Sin embargo, ha de observarse que la motivación económica aisladamente considerada no explica por completo el régimen del MT, pues a ella ha de unirse el objetivo de la calidad, como explicita el artículo 19.2 LTA, que no duda en afirmar que «la finalidad esencial para la declaración de Municipio Turístico es promover la calidad en la prestación de los servicios municipales al conjunto de la población turística asistida mediante una acción concertada de fomento». Esta finalidad, que reitera en términos muy similares el artículo 1.2 DMTA y que ya estaba presente en la L99 (artículo 6.2) y en el D//2002 (preámbulo y artículo 1.2) ${ }^{11}$, impregna ahora en mayor medida la nueva regulación, como habremos de ir viendo.

Por último, esta aproximación a los fines de la regulación nos permite ya afirmar que, aun cuando distintos autores han conectado el régimen del MT con la previsión contenida en el artículo 30 de la Ley 7/1985, de 2 de abril, Reguladora de las Bases del Régimen Local (LRBRL) ${ }^{12}$, no existe esa vinculación en el caso de Andalucía ${ }^{13}$. Como habremos de ver, el régimen del MTA se traduce en la asunción de unos compromisos para obtener determinadas ventajas, por lo que es factible aun cuando no existiera el artículo $30 \mathrm{LRBRL}^{14}$.

\section{PREMISA Y REQUISITOS SUSTANTIVOS PARA ALCANZAR LA CONDICIÓN DE MUNICIPIO TURÍSITICO}

\section{III.1. Premisa para alcanzar la condición de municipio turístico: el número de habitantes}

La premisa para poder obtener la condición de MTA es la de contar con una población de derecho no superior a cien mil habitantes (artículo 1.3 DMTA). Así estaba ya previsto en la disposición adicional primera de la L99, que optó porque las medidas de promoción y fomento del turismo de las ciudades cuya población superara la cifra fueran objeto de un tratamiento específico en el Plan General del Turismo. Curiosamente, la LTA no recoge el límite máximo de población de derecho, aunque el artículo 15.1 establece que «a solicitud de los municipios, las ciudades con población de derecho superior a los cien mil habitantes podrán ser objeto de planes turísticos específicos para la promoción y fomento del turismo».

Importa destacar que se ha suprimido el requisito de que el municipio tenga más de cinco mil habitantes, introducido en la reforma de 2006 (artículo 2.1 D/2002, en la nueva redacción dada por el D/2006) y de dudosa legalidad ${ }^{15}$.

\section{III.2. Los requisitos sustantivos para alcanzar la condición de municipio turístico}

Los requisitos propiamente dichos no los establece con carácter exhaustivo la LTA (artículo 19.1), como tampoco lo hacía la L99. Es el DMTA el que precisa los requisitos para la declaración de MTA conforme veremos a continuación.

10 2003: 56; 2017: 71.

11 SANZ DOMÍNGUEZ subrayó que con la figura del MT no sólo se buscan soluciones a las dificultades financieras y a la necesidad de cubrir la demanda de servicios en épocas de masificación sino, además, garantizar la calidad de los servicios turísticos en su conjunto (2003: 346 y 347). Vid. con carácter general SUAY RINCÓN y RODRÍGUEZ GONZÁLEZ, 1999: 84 y 85.

12 Entre otros, GALLARDO CASTILLO, 1996: 53 y 54; 2001: 91; GUILLÉN GALINDO, 1999: 57; SUAY RINCÓN y RODRÍGUEZ GONZÁLEZ, 1999: 71 y sS.; LASARTE ÁLVAREZ y ADAME MARTÍN, 2005: 423; GIL CASIÓN, 2011: 159, nota 259; y BOUAZZA ARIÑO, 2012: 263. RAZQUÍN LIZÁRRAGA señala la conexión, si bien aclara que la legislación autonómica en la materia no trata de ofrecer soluciones organizativas (2000: 43 y 48 y 49); y con carácter general, CARBONELL PORRAS apunta que «para el Derecho positivo los regímenes municipales especiales no implican necesariamente el establecimiento de un régimen diferenciado de organización, sino concretas previsiones en aspectos diversos del régimen municipal» (2007: 780). Igualmente, CALONGE VELÁZQUEZ y VILLAREJO GALENDE concluyen que no hay un verdadero estatuto de MT (2000: 333, 343 y 344).

${ }^{13}$ En cambio, otros autores consideran que el fundamento del MT se encuentra en el citado artículo e incluyen el caso de Andalucía (ILDEFONSO HUERTAS, 2003: 188 y 189 y ROMÁN MÁRQUEZ, 2008: 1199 y 1200).

${ }^{14}$ En esta línea, BERMEJO VERA (2001: 246) ha sostenido que «anunciar transferencias económicas a modo de compensaciones por gasto, anunciar formalmente la ampliación de la capacidad tributaria del Ente municipal turístico, o establecer prestaciones municipales obligatorias siempre remitiendo a los instrumentos de colaboración o cooperación, no es más que redundar sobre lo que es viable sin habilitaciones reguladoras especiales».

15 Coincido pues con FERNÁNDEZ RAMOS, 2017: 75. 


\section{III.2.1. La población turística asistida}

El primer requisito viene referido a la población turística asistida. El artículo 19.3 LTA considera que es «[I]]a constituida por quienes no ostenten la condición de vecinos o vecinas del municipio pero tengan estancia temporal en el mismo por razones de visita turística o pernoctación en alojamientos turísticos»; y añade que «[s]u determinación se efectuará por los medios de prueba que reglamentariamente se establezcan». El artículo 2.a) DMTA reproduce el concepto y detalla cuándo se considera que se alcanza el requisito. En concreto, ello sucede si se cumple al menos uno de los dos condicionantes que señala: a) visitas turísticas; b) pernoctaciones. La LTA ha prescindido del requisito del número de viviendas de segunda residencia, presente en la L99 y en el D/2002 ${ }^{16}$ hasta su modificación por el D/2006 ${ }^{17}$, esto último, a mi juicio, de manera ilegal.

Por lo que respecta a las visitas turísticas, se ha de acreditar, mediante el conteo diario de las que tienen lugar en el principal recurso turístico del municipio, que su número en el último año natural es, al menos, cinco veces superior al de la población de derecho según la última cifra oficial de padrón municipal, siempre que dicha afluencia se encuentre repartida en más de treinta días al año.

Este condicionante se endurece respecto de la regulación anterior porque se concreta el parámetro de comparación con la referencia al último año natural; y también porque el conteo de las visitas se predica del «principal recurso turístico del municipio» y no de «los recursos turísticos del municipio» ${ }^{18}$.

Por otra parte, la circunstancia de que a efectos de la constatación de la visita turística solo se tenga en cuenta la que se realiza al recurso turístico impide que se pueda computar la sola estancia en el municipio sin visitar espacios concretos en los que se tome razón de ello, lo que no es coherente con algunos de los elementos que considera el DMTA para estimar que existe una oferta turística, como es el caso de los recursos culturales (distintos de los patrimoniales o naturales) o etnográficos ${ }^{19}$. Por eso coincido con RIVERO YSERN en que hubiera sido oportuna la libertad de medios de prueba ${ }^{20}$.

Sin embargo, se ha prescindido del concepto de visitante que incluía el artículo 2 del D/2002, de modo que puede interpretarse que no se excluyen las visitas turísticas al principal recurso turístico del municipio que realizan quienes pernoctan en establecimientos de alojamiento turístico ${ }^{21}$.

En cuanto a las pernoctaciones, se exige que, de acuerdo con los últimos datos oficiales elaborados por la consejería competente en materia de turismo sobre pernoctaciones en los establecimientos de alojamiento turístico previstos en el artículo 40 LTA, se tenga un número de pernoctaciones diarias en media anual (pernoctaciones al año/365) superior al diez por ciento de la población de derecho del municipio, o bien alcanzar ese porcentaje durante al menos tres meses al año, computándose para ello la media diaria mensual (pernoctaciones al mes/30).

Los criterios para determinar el número de pernoctaciones no han cambiado. Interesa subrayar que la nueva regulación no da entrada a las que tienen lugar en viviendas con fines turísticos y en viviendas turísticas de alojamiento rural, en la misma línea que el D/2002. Estas viviendas no tienen la consideración de establecimientos turísticos y, dado que el artículo 2.a).2 DMTA sólo se refiere a las pernoctaciones en estos y no hace ninguna mención expresa a ellas ${ }^{22}$, tales pernoctaciones no se tienen en cuenta a efectos de la declaración de MTA. A mi juicio, se trata de una opción incoherente con las finalidades que persigue la figura del MT; en este sentido, la exclusión de estas viviendas de la categoría de establecimientos turísticos se ex-

16 En la versión original del artículo 2.1 del D/2002, debía cumplirse alguno de los requisitos referidos a pernoctaciones diarias, número de viviendas de segunda residencia o número de visitantes; o bien con carácter acumulativo la mitad de las exigencias referidas a pernoctaciones diarias y número de viviendas de segunda residencia.

17 Tras la reforma, se exigió el cumplimiento de uno de los dos requisitos, referidos a pernoctaciones y número de visitantes. El preámbulo del D/2006 explicaba que «no en todos los casos puede concebirse el fenómeno turístico como causa del exceso de la segunda residencia, sino que existen otros hechos, al margen del turismo, que motivan este crecimiento, no debiendo configurarse este exceso como circunstancia habilitante de la declaración de Municipio Turístico, sin perjuicio de que su impacto en la población turística asistida sea tenido en cuenta en la cuantificación de los convenios que celebre la Administración Autonómica».

18 Sin embargo, el artículo 5 del Decreto (redacción de 2006), que regulaba la documentación que había que acompañar a la solicitud de MT, exigía un «certificado que acredite las visitas realizadas al recurso turístico más visitado». En la redacción original, el artículo 2.1.c) sí se refería al «recurso turístico de mayor afluencia del municipio».

19 ROMÁN MÁRQUEZ (2008: 416) señaló la dificultad de computar el número de quienes visitan los recursos naturales.

20 2008: 127

21 Con todo, el artículo 2.a) sí distingue entre quienes tienen estancia temporal «por razones de visita turística o pernoctación».

22 Lo que sería factible porque el artículo 19.3 LTA se refiere a «pernoctación en alojamientos turísticos», sin exigir que se trate de establecimientos de alojamiento turístico. 
plica porque la actividad a la que sirven de soporte no es la principal del propietario ${ }^{23}$, pero ello, obviamente, no tiene nada que ver con la circunstancia de que en ellas tienen lugar, salvo algún caso excepcional, las pernoctaciones de quienes no forman la población de derecho.

\section{III.2.2. La oferta turística}

El segundo requisito es el de la oferta turística. Aunque el artículo 6.1 L99 ya lo exigía, el D/2002 no precisó nada al respecto. Con arreglo al artículo 2.b) DMTA,

«la oferta turística con la que cuente el municipio, sustentada en sus recursos patrimoniales, naturales, culturales o etnográficos, deportivos y de ocio, ha de tener una consistencia y atractivo tal que sea capaz de generar un flujo de visitantes hacia el mismo. El municipio también ha de disponer de una infraestructura turística mínima conforme a su realidad socioeconómica y geográfica para poder satisfacer las necesidades de la población turística asistida».

Como se aprecia, se trata de una formulación sustentada en referencias valorativas que, por una parte, modula el requisito de las pernoctaciones porque en la práctica resta operatividad a las que tengan lugar por razones distintas de los recursos patrimoniales, naturales, culturales o etnográficos, deportivos y de ocio 24 ; $y$, por otra parte, el exigir una cierta infraestructura turística, avala la consideración de que la calidad no es solo un objetivo de esta regulación sino que, además, el previo esfuerzo orientado a ella del municipio que aspira a ser MTA es en sí mismo un requisito ${ }^{25}$. En todo caso, la formulación engloba condicionantes que responden a algunos de los elementos de valoración que se enumeran en el artículo ${ }^{26}$, de modo que se aprecia un cierto solapamiento.

\section{III.2.3. El plan municipal de calidad turística}

El artículo 19.1 LTA prevé como uno de los requisitos necesarios el contar un plan municipal de calidad turística que contemple las medidas de mejora de los servicios y prestaciones. Un «plan turístico municipal o instrumento de planificación turística similar» de «duración no inferior a la cuatrienal» ya había sido previsto en el artículo 3.4 D/2002 como un elemento de valoración para la declaración de MT; en la reforma de 2006 se prescindió de la referencia al «instrumento de planificación turística similar» y de la duración mínima del plan [artículo 3.c) D/2002 reformado].

El artículo 2.c) DMTA solo menciona que el plan municipal deberá estar vigente tanto en el momento de la solicitud como en el caso previsto en el artículo $15.3^{27}$ y ajustarse a las grandes líneas estratégicas de la planificación turística de la Junta de Andalucía, tal y como en su día reclamó la doctrina ${ }^{28}$. Es el artículo 5.e) el que, al detallar la documentación que ha de acompañar a la solicitud de declaración de MTA, especifica su contenido mínimo:

${ }^{23}$ Vid. el preámbulo del Decreto 28/2016, de 2 de febrero, de las viviendas con fines turísticos y de modificación del Decreto 194/2010, de 20 de abril, de establecimientos de apartamentos turísticos.

${ }^{24}$ La capacidad para generar un flujo de visitantes es el índice que se emplea para considerar la existencia de oferta turística. En buena medida, el flujo de visitantes como requisito ya está considerado en el de las pernoctaciones. De ahí que en esta parte la formulación de la oferta turística se ordene a modular las pernoctaciones que son relevantes (recordemos que el DMTA ha prescindido de la noción de visitante que contenía el artículo 2.2 del D/2002 y que a lo sumo se puede considerar que lo es quien no pernocta). En otros términos, aunque un municipio cumpla con el requisito de las pernoctaciones, si no dispone de recursos patrimoniales, naturales, culturales o etnográficos, deportivos y de ocio, no podrá aspirar a la condición de MTA. Ha de notarse que en este extremo la formulación de la oferta turística no modula el requisito de las visitas turísticas, dado que lo que las define es que tengan lugar al principal recurso turístico del municipio y no la simple estancia.

${ }^{25}$ Así lo indicó ROMÁN MÁRQUEZ respecto de la L99 y el D/2002 (2008: 425 y 426). Con anterioridad, RIVERO YSERN subrayó el valor que confería la Ley citada a la actitud del municipio (2000: 87 y 2001: 204).

${ }^{26}$ Así, la existencia de oficinas de turismo, de recursos turísticos en el término municipal declarados de interés turístico o de interés cultural, de plazas de alojamiento inscritas en el Registro de Turismo de Andalucía y de oficinas municipales donde se facilite información a la población turística asistida sobre sus derechos como personas consumidores y usuarias; a lo que se añade la ubicación del término municipal, total o parcialmente, en alguno de los espacios naturales protegidos de Andalucía o sus Áreas de Influencia Socioeconómica [artículo 3, letras e), f), g), p) y k), respectivamente].

${ }^{27}$ El artículo 15.3 establece, en lo que aquí interesa, la obligación de acreditar cada cuatro años ante la Consejería competente el cumplimiento de los requisitos que dieron lugar a la declaración. Por eso la referencia a dicho artículo 15.3 en este lugar puede considerarse ociosa. No lo es en cambio la puntualización de que el plan debe estar vigente, ya que con arreglo 5.3.e) D/2002, en su versión original, bastaba con la aportación de un avance del plan.

28 FERNÁNDEZ RAMOS, 2003: 68. 
1. Diagnóstico de la actividad turística en el municipio en el que se detallen necesidades y problemas del sector, visitantes y turistas que recibe y sus motivaciones, incluyendo estadísticas diferenciadas por sexo tanto con respecto al empleo como al turismo. 2. Los objetivos que persigue el plan municipal de calidad turística. 3. La descripción de las actuaciones de mejora de los servicios y prestaciones vinculados con la actividad turística, con indicación de su presupuesto y calendario de ejecución. 4. Los mecanismos de seguimiento y evaluación del plan municipal de calidad turística.

En buena medida, estos contenidos ya se encontraban previstos en el artículo 3.4 del D/2002 (regulación de 2002) por referencia al plan turístico municipal ${ }^{29}$.

Nada se dice sobre la valoración del plan que se presente; en particular, no se establece ningún estándar o medida de la calidad a la que se ordene. A mi juicio, el diagnóstico de la actividad turística es su piedra angular, de manera que la primera apreciación debe girar en torno a su suficiencia y acierto. Constatados estos, debe examinarse la coherencia que guardan los objetivos con el diagnóstico y la que presentan las actuaciones de mejora con unos y otro, así como la idoneidad de los mecanismos de seguimiento y evaluación en atención a las actuaciones concretas que se hayan propuesto.

La nueva funcionalización del plan municipal de calidad turística como requisito y no como elemento de valoración, además de evidenciar que la calidad es uno de los objetivos de esta regulación, permite considerar que se pretende que sólo alcancen la condición de MTA los municipios que a priori hayan demostrado su disposición para realizar un esfuerzo de mejora en la atención de las necesidades y problemas que se suscitan en el sector turístico. La circunstancia de que no se hayan querido establecer estándares concretos de mejora avala que se exige una actitud o disposición.

\section{III.2.4. Los elementos de valoración}

El cuarto requisito consiste en acreditar el cumplimiento de al menos diez de los elementos de valoración que recoge el artículo 3 [artículo 2.d)].

Antes de proceder a su exposición, conviene recordar que la L99 había avanzado dos requisitos de valoración y que el D/2002 añadió finalmente otros, luego modificados por el D/2006. Este esquema, como bien apreciara la doctrina, introducía en la decisión de otorgar la condición de MT «un cierto margen de valoración, no ya reglada» (FERNÁNDEZ RAMOS) ${ }^{30}$.

La LTA sigue la misma pauta que su antecesora y también expresa dos elementos de valoración, en la misma línea además ${ }^{31}$. El DMTA, sin embargo, añade otros quince y, lo que resulta más llamativo, se aparta de su precedente porque prescribe que se ha de acreditar el cumplimiento de al menos diez. De este modo, los elementos de valoración adquieren una funcionalidad distinta, pues en definitiva son ahora también requisitos. La cuestión que en consecuencia se plantea es la de sí la acreditación del cumplimiento de los diez «elementos de valoración» es suficiente o, por el contrario, la Administración andaluza puede valorar el resto de los elementos para, en su caso, resolver negativamente. Y, en relación con ello, si el DMTA se ajusta en este punto a la LTA.

A mi juicio, la exigencia expresa y terminante del cumplimiento de diez de los elementos de valoración acota el examen a los que haya seleccionado el municipio y resta fuerza a la caracterización de la decisión sobre la condición de MT como discrecional, pues no tiene sentido la imposición de un mínimo (la concurrencia de los diez elementos) para a continuación denegar la solicitud a resultas de la valoración realizada sobre otros elementos (como máximo siete) que no se exigen ${ }^{32}$; cuestión distinta es, claro está, los términos en que están redactados muchos de los elementos, que precisamente apuntan a una actividad de valoración antes

29 La reforma de 2006 prescindió del apartado cuarto del artículo 3, conformándose su letra c) con la exigencia de que el plan contuviera al menos «un diagnóstico de la situación turística, así como la propuesta de actuaciones para mejorar la oferta del turismo en el municipio».

30 2003: 64 y 2017: 75 y 80. En opinión de RIVERO YSERN, la Ley configuraba la declaración de MT como una «decisión reglada en la que hay que manejar diversos conceptos jurídicos indeterminados» (2000: 88 y 2001: 205); posteriormente consideró que la valoración era en gran parte discrecional (2008: 130; vid. no obstante la pág. 135).

31 Artículo 20.1: «a) Los servicios públicos básicos que presta el municipio respecto a la vecindad y a la población turística asistida, b) Los servicios específicos que tengan una especial relevancia para el turismo».

32 Según el artículo 7.2 DMTA, los actos de instrucción que realiza la Secretaría General en el procedimiento son los «necesarios para la determinación, conocimiento y comprobación de datos y criterios en virtud de los cuales deba examinarse la idoneidad para ser declarado turístico el municipio solicitante». Lo resaltado en cursiva indica, a mi juicio, que la idoneidad no ha de examinarse a la luz de todos los elementos de valoración. 
que a una actividad de constatación. En cuanto a si el DMTA se ajusta en este punto a la LTA, no plantea ningún problema la ampliación de los requisitos porque la Ley lo consiente expresamente al remitir su fijación al reglamento. Sin embargo, el Decreto no se «ajusta» a la Ley porque al convertir los elementos de valoración en requisitos hace desaparecer la discrecionalidad propia de aquellos; cuestión distinta es que pueda calificarse el Decreto como ilegal, pues al cabo es la propia Administración autonómica la que se ha autolimitado con carácter general y abstracto, pudiéndose justificar esta opción en el principio de seguridad jurídica.

En todo caso, resulta paradójico el que la formulación del requisito referido a la oferta turística [artículo 2.b) DMTA] se ajuste más a lo que es un elemento de valoración, mientras que los que se enuncian como «elementos de valoración» (artículo 3 DMTA) sean, de suyo, requisitos, bien que enunciados muchos de ellos en términos valorativos. Sobre este particular, el DMTA rompe con el esquema acuñado en el D/2002 que, como subrayara la doctrina ${ }^{33}$, configuró los requisitos como elementos estrictamente reglados y arbitró una importante esfera de discrecionalidad en lo relativo a los elementos de valoración.

Los elementos de valoración son, como ya se ha indicado, diecisiete. A continuación, examinaremos cada uno de ellos.

a) Servicios públicos básicos que, según lo previsto en la normativa básica estatal sobre Régimen Local, preste el municipio respecto a la vecindad y a la población turística asistida, cuyo refuerzo se precise para satisfacer sus necesidades.

Este elemento de valoración se formula en términos distintos respecto de las regulaciones anteriores ${ }^{34}$, ya que en lugar de «servicios mínimos» se alude a «servicios públicos básicos» ${ }^{35}$ y se puntualiza que el refuerzo de los servicios sea preciso para satisfacer las necesidades, pudiéndose interpretar que se refiere a una situación de déficit en la prestación. Lo que debe valorarse, pues, no es ni el esfuerzo presupuestario que en su caso se esté haciendo para prestar los servicios (regulación de 2002), ni las actuaciones municipales que en su caso estén teniendo lugar (redacción de 2006), sino justamente la necesidad de reforzar la prestación.

b) Servicios específicos prestados por el municipio que tengan una especial relevancia para el turismo, tales como salud pública, medio ambiente urbano, transporte colectivo urbano, protección civil y seguridad ciudadana y que asimismo cumplan con los parámetros de sostenibilidad ambiental, social y económica.

Este elemento de valoración también presenta una redacción distinta a la de 2002 y 2006 . De nuevo, no es el esfuerzo presupuestario el que debe valorarse (regulación de 2002); aunque tampoco es la necesidad de reforzar la prestación, como sucedía con el anterior elemento. Lo que debe valorarse son los servicios que efectivamente se prestan, al igual que se dispuso en la reforma de 2006. Respecto de esta última, se registran variaciones en las áreas aunque algunas de ellas son más nominales que reale ${ }^{36}$ y se añade que los servicios cumplan con los parámetros de sostenibilidad ambiental, social y económica, cláusula que a mi juicio es excesivamente amplia e indeterminada, pues no se precisa nada acerca de tales parámetros, sin que pueda descartarse que en algún caso pueda desplegar cierta operatividad.

La inclusión de este elemento de valoración, dada su funcionalidad como requisito, favorece a los municipios de mayor población, pues los que se enuncian son servicios mínimos que han de prestar los municipios según el número de habitantes (artículo 26 LRBRL). Así, un municipio de más de cincuenta mil habitantes sólo tendría realmente que reunir nueve requisitos de los restantes de la lista. Es cierto que se matiza que los servicios han de cumplir con los parámetros de sostenibilidad ambiental, social y económica, lo que en su caso podría determinar que un municipio de más de cincuenta mil habitantes no alcanzara el requisito; pero como ya se ha dicho, la indeterminación de la cláusula le resta eficacia. Para municipios con menor número de habitantes el cumplimiento del elemento sí tiene verdadera significación y es indicativa de un esfuerzo previo; por otra parte, ha de notarse que hay más posibilidades de que se pueda concluir que la prestación de un servicio sobre el que no pesa obligación atendiendo al número de habitantes incumple el parámetro de sostenibilidad económica.

c) Disponer de planes de accesibilidad para la supresión de barreras arquitectónicas, urbanísticas y de transporte, así como otras actuaciones municipales, con incidencia en la actividad turística, orientadas a la accesibilidad universal.

\footnotetext{
33 ROMÁN MÁRQUEZ, 2008: 433 y 434.

${ }_{34}$ Originariamente, el artículo $3.1 \mathrm{D} / 2002$ se refería al «esfuerzo presupuestario que realiza el municipio en relación con la prestación de servicios mínimos que, de conformidad con el artículo 26 de la Ley 7/1985, de 2 de abril, Reguladora de las Bases del Régimen Local, presta efectivamente el municipio». En la redacción de 2006 se aludía a «[l]as actuaciones municipales en relación a los servicios mínimos que debe prestar el municipio respecto a los vecinos y a la población».

${ }^{35}$ En consonancia con el artículo 92.2.d) del reformado Estatuto de Autonomía.

36 En 2006 se consideraron la «salubridad pública e higiene en el medio urbano y natural, transporte público de viajeros, protección civil y seguridad ciudadana, así como otros que sean de especial relevancia turística».
} 
Los planes de accesibilidad ya estaban contemplados en el D/2002, primero como contenido del planeamiento urbanístico general (regulación de 2002) y, después, como elemento de valoración autónomo (regulación de 2006); se añaden ahora las otras actuaciones municipales con incidencia en la actividad turística, orientadas a la accesibilidad universal. A mi juicio, la mención a los planes de accesibilidad resulta sorprendente porque su aprobación ya venía impuesta por la Ley 1/1999, de 31 de marzo, de Atención a las Personas con Discapacidad en Andalucía ${ }^{37}$, cuya disposición adicional quinta estableció que los planes de adaptación y supresión de barreras debían ser elaborados en el plazo de dos años desde la entrada en vigor de la ley y realizados en un plazo máximo de diez años. Parece, pues, que la obligación no ha sido en todos los casos cumplida ni exigida. En la actualidad, el artículo 53 de la Ley 4/2017, de 25 de septiembre, de los Derechos y la Atención a las Personas con Discapacidad en Andalucía, dispone que.

«[l]a Administración de la Junta de Andalucía y las Administraciones locales deberán aprobar, en las condiciones y plazos que se determinen en la normativa aplicable, planes de accesibilidad para adecuar los entornos susceptibles de ajustes razonables a las exigencias normativas de accesibilidad. Los planes de accesibilidad deberán ser revisados y actualizados, en su caso, cada cinco años».

Dado que el Decreto 293/2009, de 7 de julio, por el que se aprueba el reglamento que regula las normas para la accesibilidad en las infraestructuras, el urbanismo, la edificación y el transporte en Andalucía, no señala plazo para la elaboración de los planes de accesibilidad, cobra sentido, tristemente, la previsión de estos planes como elemento de valoración, que ciertamente favorecerá a aquellos municipios que sí hayan cumplido las obligaciones en la materia.

d) Inversiones previstas en el presupuesto municipal para la promoción e infraestructuras turísticas.

Este elemento ya estaba previsto en el D/2002 [artículo 3.a) de la regulación de 2006]. Coincido con ROMÁN MÁRQUEZ $Z^{38}$ en que con el mismo se valora el grado de implicación del municipio en la actividad turística, no tanto por el montante que se dedique a estas finalidades sino por su proporción en relación con el presupuesto total.

e) Existencia de oficinas de turismo accesibles convenientemente señalizadas y equipadas.

Originariamente, el artículo 3.1.e) D/2002, al regular los elementos de valoración, incluyó la información turística como una de las áreas en las que se consideraban prioritarias las actuaciones y prestación de servicios específicos. En la reforma de 2006 este elemento de valoración cobró sustantividad propia y se formuló en parecidos términos a los ahora vigentes [artículo 3.d) del Decreto reformado], de modo que dio entrada a la valoración de la existencia de oficinas de turismo de titularidad distinta de la municipal.

Las oficinas de turismo, por tanto, pueden ser de titularidad pública o privada, como prevé el artículo 3.1 del Decreto 202/2002, de 16 de julio, de Oficinas de Turismo y de la Red de Oficinas de Turismo de Andalucía, siendo irrelevante a los efectos de la declaración de MTA que estén integradas o no en la Red de Oficinas de Turismo de Andalucía ${ }^{39}$. Dado que solo se mencionan las oficinas, no se consideran los puntos de información turística ${ }^{40}$.

f) Existencia de recursos turísticos en el término municipal, declarados de interés turístico o de interés cultural.

En la reforma de 2006 se introdujo como nuevo elemento de valoración «la relevancia de los recursos turísticos existentes en el término municipal, con especial atención a los bienes declarados de interés cultural» [artículo 3.e) D/2002, reformado] ${ }^{41}$. Ahora, el elemento de valoración referido a los recursos turísticos se torna más exigente, pues es preciso que estén declarados de interés turístico o de interés cultural. Por otra parte, se advierte con claridad la distinta funcionalidad que adquieren los elementos de valoración, puesto que no se trata de enjuiciar o de valorar sino que, dado por supuesto un estándar de relevancia (la declaración de interés turístico o de interés cultural), basta con acreditar su existencia.

g) Plazas de alojamiento inscritas en el Registro de Turismo de Andalucía.

De entrada, este elemento de valoración, que es nuevo, plantea la dificultad del sentido que pueda tener atendiendo a la nueva funcionalidad de los elementos de valoración, configurados realmente como

37 Sobre esta circunstancia llamó la atención FERNÁNDEZ RAMOS, 2003: 67, nota 50 y 2017: 82, nota 145.

38 2008: 427, 1209 y 1210.

39 FERNANDEZ RAMOS consideró que las oficinas debían estar integradas en la Red (2003: 65).

40 Es el «establecimiento turístico que, con carácter permanente o temporal, facilita a sus usuarios orientación, asistencia e información turística especializada, bien sobre un determinado evento o fiesta de relevancia turística, bien sobre unas zonas o recursos turísticos concretos» [artículo 2.c) del Decreto 202/2002].

${ }^{41}$ Como en su día postuló FERNANDEZ RAMOS, 2003: 70. 
requisitos. $Y$ es que ni se cuantifican las plazas de alojamiento ni se ofrece precisión alguna que permita considerar cumplido el requisito. A mi juicio, puede interpretarse que se ha de contar con un número de plazas razonablemente superior a la demanda real existente en el momento de solicitar la declaración de MTA. De este modo, las plazas de alojamiento serían un indicador de un esfuerzo previo adicional al que exige el cumplimiento del requisito de la oferta turística ${ }^{42}$, teniendo en cuenta que en ambos casos (para cumplir el requisito de la oferta turística y como elemento de valoración), el esfuerzo es realizado no por el municipio sino en el municipio.

h) Adopción de medidas de defensa y restauración del patrimonio cultural y urbano.

Al igual que otros elementos de valoración, este ya fue introducido en la reforma llevada a cabo en 2006 [artículo 3.f) D/2002], con buena acogida por parte de la doctrina ${ }^{43}$. Como con claridad se aprecia, se trata de otro indicador del esfuerzo previo del municipio.

i) Existencia de Ordenanzas Fiscales y de Medio Ambiente, en las que figuren debidamente recogidas medidas para la preservación de los valores medioambientales.

La reforma de 2006 dio entrada a este elemento de valoración. En su momento se interpretó como una muestra de la preocupación por la calidad global de los destinos turísticos (ROMÁN MÁRQUEZ ${ }^{44}$ ). En la actualidad, puede reiterarse esta consideración, subrayando que, efectivamente, el elemento revela la preocupación por la calidad global y no por la calidad turística en sí misma considerada y, por otra parte, que complementa de modo especial el elemento de valoración expresado en la letra $h)^{45}$. Finalmente, debe considerarse que la existencia de estas ordenanzas no es per se significativa, pues lo relevante no es tanto contar con este tipo de normas sino que de su contenido se deduzca un mayor nivel de protección del que resulta obligado por las normas estatales y autonómicas de aplicación en cada caso.

j) Adopción de medidas tendentes a corregir las desigualdades entre mujeres y hombres, así como las adoptadas en materia de violencia de género, con incidencia en la actividad turística.

Este elemento de valoración es nuevo y responde a los mandatos incluidos en los artículos 5 y 6.2 de la Ley 12/2007, de 26 de noviembre, para la promoción de la igualdad de género en Andalucía, que también han encontrado cumplimiento en los artículos 31 y 56.4 LTA.

k) Ubicación del término municipal, total o parcialmente, en alguno de los espacios naturales protegidos de Andalucía o sus Áreas de Influencia Socioeconómica.

Con distinta perspectiva, el D/2002 contempló como elemento de valoración la ubicación en el término municipal, de modo total o parcial, de alguno de los espacios naturales protegidos de Andalucía (artículo 3.2). La reforma de 2006 modificó la redacción del elemento de valoración, situando en primer plano la ubicación del término municipal en alguno de estos espacios [artículo 3.h) del Decreto reformado]. Esta perspectiva es la que se mantiene, añadiéndose la posibilidad de que el término municipal se encuentre ubicado, toral o parcialmente, en las áreas de influencia socioeconómica.

La doctrina ha manifestado puntos de vista distintos en torno a la significación de este elemento de valoración, considerándolo como una muestra de la aproximación del MT al municipio de interés turístico ${ }^{46} \mathrm{y}$, en otro sentido, como un factor indicativo del sacrificio económico adicional que realizan los municipios en los que concurre esta circunstancia, de modo que su funcionalidad sería la de justificar una rebaja en la exigencia del resto de los elementos que se han de evaluar ${ }^{47}$. A mi juicio, las dos opiniones son compatibles ${ }^{48}$.

I) Adopción de medidas de protección y recuperación del entorno natural y del paisaje.

En su día, el D/2002 recogió un elemento de valoración parecido («protección y recuperación del entorno natural y del medio ambiente»), caracterizándolo como una de las áreas en las que se consideraban prioritarias las actuaciones y prestación de servicios específicos en relación con el esfuerzo presupuestario del municipio en cuanto a servicios con repercusión en el turismo; posteriormente, la reforma de 2006 lo singularizó en los términos actuales. Claramente, el elemento de valoración enlaza con el previsto en la letra

42 Recordemos que «[e]l municipio también ha de disponer de una infraestructura turística mínima conforme a su realidad socioeconómica y geográfica para poder satisfacer las necesidades de la población turística asistida» [artículo 2.b)].

43 ROMÁN MÁRQUEZ, 2008: 430.

44 2008: 430

45 Vid. el interesante estudio de BLANQUER (2004).

46 Esta es la postura que parece sostener FERNANDEZ RAMOS, 2003: 69 y 2017: 83 y 84.

47 ROMÁN MÁRQUEZ, 2008: 430 y 431.

48 De hecho, FERNÁNDEZ RAMOS señala que la introducción del elemento «tal vez puede obedecer a la finalidad de evitar la oposición por parte de determinados Gobiernos municipales a la declaración en su territorio de espacios naturales protegidos, que se ven como un obstáculo para su desarrollo económico, y, en particular, para su desarrollo turístico» (2003: 70, nota 57). 
h) en tanto que indicador del esfuerzo previo del municipio, a lo que cabe añadir que responde a la consideración del patrimonio natural como recurso turístico ${ }^{49}$ y que, como ha señalado ROMÁN MÁRQUEZ, apunta a la preocupación por la calidad global del destino turístico ${ }^{50}$.

m) Existencia de un planeamiento urbanístico que contemple las dotaciones de espacios libres y otras que cumplan las reservas mínimas previstas por la legislación urbanística, justificándose su incidencia sobre la población turística asistida.

El D/2002 se había referido a la existencia de un planeamiento urbanístico general que debía cumplir una serie de requisitos; en la reforma de 2006, la redacción de este elemento de valoración se aproximó a la actual. En particular por lo que respecta a las dotaciones, en 2002 se exigía que el sistema general de espacios libres cumpliese «los estándares mínimos de acuerdo con la legislación urbanística, referido a la suma de la población turística asistida»; en 2006 se introdujo la mención de «las dotaciones de espacios libres y otras que cumplan las reservas mínimas previstas por la legislación urbanística, referidas a la población de derecho y a la población turística asistida», de manera que, sin perjuicio de lo que seguidamente se dirá, se amplió el ámbito objetivo de la exigencia (dotaciones distintas de las de espacios libres) y se perfeccionó la redacción en lo relativo a los espacios libres ${ }^{51}$. En la actualidad, basta con justificar la incidencia sobre la población turística asistida de las dotaciones de espacios libres y otras que cumplan las reservas mínimas previstas por la legislación urbanística. Puede observarse que, aunque se valora el esfuerzo adicional que entraña la proyección de los estándares sobre la población turística asistida, ello no es lo mismo que cumplir los estándares mínimos con respecto a la suma de la población de derecho y de la población turística asistida. Con todo, la actual redacción es más correcta, dado que los únicos estándares que la Ley 7/2002, de 17 de diciembre, de Ordenación Urbanística de Andalucía, referencia por el número de habitantes son los referidos a «parques, jardines y espacios libres públicos» [artículo 10.1.A).c.1)]; de ahí que en 2006 se incurriera en el error de ampliar la exigencia a esas otras dotaciones distintas de los espacios libres y que hoy la norma se conforme con la justificación de la incidencia de todas las dotaciones sobre la población turística asistida.

n) Actuaciones para potenciar la movilidad sostenible no motorizada o la motorizada basada en energías alternativas.

Nos encontramos ante un elemento de valoración nuevo que responde al principio de desarrollo territorial y urbano sostenible que proclama el artículo 3 del Texto Refundido de la Ley de Suelo y Rehabilitación Urbana, aprobado por Real Decreto Legislativo 7/2015, de 30 de octubre, claramente conectado con lo dispuesto en su apartado 3.f). Aun cuando su inclusión en 2017 no tiene carácter extraordinario, revela la importancia del «turismo como campo de pruebas para una mejor gestión ambiental» (FERREIRA y NOGUEIRA ${ }^{52}$ ) y puede considerarse como un indicador del esfuerzo previo del municipio.

ñ) Distintivos y certificaciones de calidad de los recursos y servicios turísticos que tenga el municipio.

También se trata de un elemento de valoración novedoso que, como se aprecia, apunta directamente al esfuerzo previo del municipio en pos de la calidad. Esta, la calidad, no se adjetiva, por lo que deben ser considerados tanto los distintivos y las certificaciones de calidad específicamente turísticas como los de índole ambiental ${ }^{53}$.

o) Declaraciones de zona de gran afluencia turística a efectos de horarios comerciales concedida por la consejería competente en materia de comercio interior.

La introducción de este elemento de valoración supone una novedad: no estaba previsto en el D/2002 54 ni fue incorporado en la reforma llevada a cabo por el D/2006. A mi juicio, es un elemento que en cierto modo se solapa con algunos de los que el DMTA considera genuinos requisitos, dadas las circunstancias que se consideran a los efectos de la declaración ${ }^{55}$. Coincido con CALONGE VELÁZQUEZ

49 TUDELA ARANDA (1996: 340) se ha referido a los recursos medioambientales como «recursos turísticos de primerísimo orden», destacando (págs. 291 y 292 y 339 y ss.) la incidencia del Plan Marco de Competitividad del Turismo Español, Ministerio de Industria, Comercio y Turismo, Secretaría General de Turismo, Madrid 1992; vid. también TUDELA ARANDA, $2001: 133$.

50 2008: 430.

51 En la redacción inicial iba de suyo que el sistema general de espacios libres debía cumplir los estándares mínimos referidos a la población de derecho.

52 FERREIRA FERNÁNDEZ y NOGUEIRA LÓPEZ, 2001: 268.

53 FERREIRA FERNÁNDEZ y NOGUEIRA LÓPEZ, 2001: 282 y 283.

54 Sobre ello llamó la atención FERNÁNDEZ RAMOS, precisando que se trataba de un elemento que, no obstante su omisión, debía ser valorado (2003: 59).

55 Vid. el artículo 20.3 del Texto Refundido de la Ley del Comercio Interior de Andalucía, aprobado por Decreto Legislativo 1/2012, de 20 de marzo, en la redacción dada por el Decreto-ley 1/2013, de 29 de enero, así como el artículo 2 del Decreto 2/2014, de 14 de 
y VILLAREJO GALENDE ${ }^{56}$ en que más bien es la declaración de MT la que debe llevar aparejada la de zona de gran afluencia turística, extremo al que se muestra sensible el artículo 2.1.c) del Decreto 2/2014, de 14 de enero, por el que se regulan los criterios y el procedimiento para la declaración de zonas de gran afluencia turística, a efectos de horarios comerciales. En todo caso, dado que es el municipio el que inicia con su solicitud el procedimiento para la declaración de zona de gran afluencia turística ${ }^{57}$, puede considerarse que el elemento toma en consideración el interés previo del municipio por atender a la población turística.

p) Oficinas municipales donde se facilite información a la población turística asistida sobre sus derechos como personas consumidoras y usuarias.

El artículo 3 cierra la enumeración de los elementos de valoración con esta referencia, nueva respecto de la regulación anterior. Debe tenerse en cuenta que la legislación de consumo de Andalucía no obliga a la existencia de oficinas municipales de información al consumidor, sino que se conforma con prever su fomento por parte de la administración autonómica, aunque, eso sí, de forma especial «[e]n los municipios de alto grado de población flotante, en la forma en que se establezca reglamentariamente» [artículo 21.2.e) de la Ley 13/2003, de 17 de diciembre, de Defensa y Protección de los Consumidores y Usuarios de Andalucía]. Por eso tiene sentido la inclusión de este elemento que considera el esfuerzo previo del municipio, aunque se podría haber prescindido de su mención independiente y haberlo incluido en la letra b), referida a servicios de especial relevancia para el turismo.

La conclusión evidente que cabe extraer del conjunto de los elementos de valoración es la de su carácter heterogéneo. Algunos de ellos avalan la consideración, ya anticipada, de que el perfil de MT presenta rasgos característicos de «municipio de interés turístico»" ${ }^{58}$. La mayoría apuntan al esfuerzo previo, en términos de calidad turística o de atención al turista, que se exige ${ }^{59}$, como ya señalara respecto de la regulación anterior ROMÁN MÁRQUEZ ${ }^{60}$. En franca minoría se encuentra el que se orienta a las necesidades financieras que plantea la circunstancia de ser un municipio con una abierta desproporción entre la población de derecho y los visitantes por razones turísticas ${ }^{61}$. Otros tienen una significación ajena al perfil de MT o solo de modo indirecto conectan con el factor turístico ${ }^{62}$. Y hay tres en particular-los de las oficinas de turismo privadas, las plazas de alojamiento y los distintivos y certificaciones de calidad obtenidos por la iniciativa privada- distintos a los demás y con un perfil peculiar, pues su concurrencia no depende ni se relaciona con esfuerzo municipal alguno ${ }^{63}$.

El recuento de los elementos que se adscriben a cada grupo, incluyendo los tres citados en último lugar, evidencia que el Decreto se ha asegurado la necesaria concurrencia de al menos dos elementos indicativos del esfuerzo previo en términos de calidad turística ${ }^{64}$, pues la suma de los restantes elementos ${ }^{65}$ no es su-

enero, por el que se regulan los criterios y el procedimiento para la declaración de zonas de gran afluencia turística, a efectos de horarios comerciales.

56 2000: 357. Vid. también MELGOSAARCOS (2011: pág. 1.207).

57 La consejería competente solo lo inicia de oficio en el supuesto previsto en la disposición adicional única del Decreto 2/2014, aplicable a municipios con más de 200.000 habitantes.

58 Letras $f$ ) y $k$ ).

59 Letras $(b), c), d), e),(h), i), l),(m), n), \tilde{n})$, o) y $p)$. Respecto de la letra $c$ ), recordemos que a la fecha de aprobación del DMTA los planes de accesibilidad locales debían estar necesariamente aprobados; la reciente Ley 4/2017, como ya se ha indicado, da sentido a su inclusión como elemento de valoración. En cuanto a la letra e), tomo ahora en consideración las oficinas de titularidad pública; lo mismo cabe precisar de la letra ñ), que se incluye en este lugar considerando que los recursos y servicios turísticos sean municipales. La letra i) se menciona considerando que las ordenanzas incorporan un mayor nivel de protección ambiental al que resulta exigible por las legislaciones estatal y autonómica.

60 2008: 425 y 426.

61 Letra a).

62 Letras i) y j). En esta ocasión, la letra i) se menciona considerando la mera existencia de ordenanzas que no incorporen un mayor nivel de protección ambiental. En cuanto a la letra j), el Consejo Consultivo de Andalucía, en su dictamen $333 / 2017$ sobre el Proyecto de Decreto, advirtió a propósito de la redacción inicial de este apartado («adopción de medidas tendentes a corregir las desigualdades entre mujeres y hombres, así como las adoptadas en materia de violencia de género») que «[d]ebería aclararse en qué medida tal previsión puede influir en la declaración como municipio turístico de Andalucía, ya que en otro caso y como medida de política general no tendría cabida en este concreto precepto»; a mi juicio, la nueva redacción del apartado, con el añadido «con incidencia en la actividad turística», supone solo una atención pro forma a la consideración del Consejo Consultivo.

63 Presumimos que el «esfuerzo» lo realiza la iniciativa privada.

64 Salvo que se trate de un municipio que por el número de habitantes venga obligado a prestar los servicios que enumera la letra b) o que haya cumplido con sus obligaciones en materia de accesibilidad.

65 Incluso aunque entre ellos se encontraran los reveladores del esfuerzo de la iniciativa privada y la existencia de unas ordenanzas fiscales y de medio ambiente que no incrementaran la protección. 
ficiente para alcanzar el número de diez que se exige. También evidencia, y así se ha destacado antes, la preponderancia de elementos de valoración que apuntan al esfuerzo previo del municipio, lo que nos lleva a plantearnos, con LLAGAS GELO ${ }^{66}$, hasta qué punto la norma no hace sino incrementar "artificialmente el impacto del turismo sobre las poblaciones con el desequilibrio que ello supone». Dicho en otros términos, la remediación del problema (las necesidades financieras) aumenta su magnitud.

\section{LOS EFECTOS DE LA DECLARACIÓN DE MUNICIPIO TURÍSITICO DE ANDALUCíA}

La declaración de MT comporta obligaciones para la Administración de la Junta de Andalucía y para el propio municipio ${ }^{67}$. Puede dar lugar además a la celebración de convenios que, a su vez, pueden generar nuevas obligaciones. Y se deja abierta la posibilidad de otras formas de colaboración interadministrativa (artículo 13.1 DMTA) ${ }^{68}$. Veámoslo a continuación, advirtiendo que soslayaremos los aspectos de índole formal de las obligaciones y de los convenios.

\section{IV.1. Las obligaciones de la Administración de la Junta de Andalucía}

La primera obligación que se impone, que más bien es un deber genérico, se formula en el artículo 14.1 DMTA en los siguientes términos:

«Para compensar el mayor esfuerzo económico adicional que realiza el Municipio Turístico de Andalucía en la prestación de los servicios, motivado por el carácter turístico del mismo, y con independencia del régimen financiero previsto para los municipios considerados como turísticos por la normativa básica estatal sobre Haciendas Locales ${ }^{69}$, la Administración de la Junta de Andalucía estará obligada a considerarlo de forma prioritaria en las acciones de ordenación y fomento de sus planes económicos cuando resulte compatible con los objetivos de los mismos y en su caso, con el carácter finalista de su financiación».

Son varias las diferencias que se detectan respecto de la regulación de 2006: 1) el deber se impone ahora al conjunto de la administración andaluza, mientras que antes solo resultaban obligadas las consejerías competente en materia de turismo y demás que suscribieran el oportuno convenio; 2) en lugar de la alusión a los planes económicos sectoriales, se matiza que la consideración prioritaria del MTA tendrá lugar cuando resulte compatible con los objetivos de los planes económicos; 3) se suprime la precisión de que se tomaría como elemento de cuantificación la población turística asistida, lo que a mi juicio resta fuerza a esta vía de financiación, si bien se comprende que el DMTA no haya querido predeterminar un parámetro de consecuencias inciertas.

Finalmente, este deber es independiente de la eventual suscripción del convenio que regulan los artículos 18 a 20, como aclara el preámbulo del DMTA. Cabe subrayar que es la vía de financiación que mejor

66 2017: 136.

67 Ambos tipos de obligaciones se recogen en la sección $4 .^{\text {a }}$ del capítulo II DMTA, que se denomina «efectos». En el D/2002 se insertaban en el capítulo III, titulado «convenios», interpretándose (RIVERO YSERN, 2008: 135) que la firma del convenio por la administración andaluza suponía el reconocimiento del «derecho del Municipio a ser beneficiario de las acciones de ordenación y fomento de sus planes económicos sectoriales». La mejora sistemática es evidente y evita confusiones acerca del carácter de estas obligaciones, que son independientes de la eventual suscripción del convenio, como por otra parte aclara el preámbulo del DMTA.

68 Vid. las propuestas de RIVERO YSERN (2005) para profundizar en el tratamiento de los municipios turísticos.

En otro orden de cuestiones, la declaración puede surtir efectos indirectos. Vid. el artículo 5.1.a) de la Orden de 25 de marzo de 2002, por la que se regulan los horarios de apertura y cierre de los establecimientos públicos en la Comunidad Autónoma de Andalucía; el artículo 1 y el apartado 1 k) del anexo de la Ley 2/2008, de 10 de diciembre de 200, que regula el acceso de los municipios andaluces al régimen de organización de los municipios de gran población; el artículo 5 de la Orden de 17 de febrero de 2003 , por la que se establecen las bases reguladoras para la concesión de ayudas para el embellecimiento de zonas con el fin de favorecer la preservación de elementos tradicionales de Andalucía; el artículo 2.1.c) del Decreto 2/2014, de 14 de enero; y la Orden de 5 de enero de 2018, por la que aprueban las bases reguladoras para la concesión de subvenciones, en régimen de concurrencia competitiva, dirigidas a favorecer la recualificación de los destinos turísticos maduros del litoral andaluz mediante el desarrollo de la Economía Digital.

69 Vid. el artículo 125 del Texto Refundido de la Ley Reguladora de las Haciendas Locales, aprobado por Real Decreto Legislativo 2/2004, de 5 de marzo. Como es sabido, la noción de municipio turístico que alberga el precepto no vincula a las Comunidades Autónomas en orden al diseño de una política propia en la materia. Y obviamente, la aplicación del artículo se realiza al margen de lo que la legislación autonómica pueda haber previsto. En la doctrina, vid. LASARTE ÁLVAREZ y ADAME MARTíN (2005: 432 y sS. y 440), ROMÁN MÁRQUEZ (2008: 394 y ss.) y BOUAZZAARIÑO (2012:277 y ss.). 
responde, al menos en teoría, a la necesidad de obtener recursos adicionales habida cuenta la desproporción entre la población de derecho y la población turística.

La segunda obligación, que es nueva, se impone a la consejería competente en materia de turismo y consiste en hacer mención a la condición de MTA en las acciones de promoción turística que sobre dicho municipio lleve a cabo (artículo 14.2).

Por último, interesa reparar en otra novedad que incorpora el DMTA al regular la documentación que se ha de acompañar a la solicitud de declaración de MTA. El artículo 5.f) exige una «memoria explicativa de aquellas actividades y servicios públicos con incidencia turística que, en el ámbito de sus competencias, tengan dificultad de implantación o de desarrollo, así como las razones que lo motivan», a lo que añade que «se deberá motivar las instalaciones y servicios de competencia autonómica que sería necesario reforzar en los períodos de mayor afluencia turística para satisfacer las necesidades de atención tanto de la comunidad vecinal como de la población turística asistida». Por consiguiente, la memoria no solo versa sobre las actividades y servicios de competencia municipal respecto de los que se aprecian dificultades sino, también, acerca de las instalaciones y servicios de competencia autonómica que es preciso reforzar. Esta mención rompe la perspectiva tradicional, que asocia la afluencia de visitantes con las dificultades municipales, para apuntar de lleno a las instalaciones y servicios autonómicos, que igualmente pueden verse afectados. Ello no obstante, el DMTA no extrae ninguna consecuencia precisa de ello, pues nada hay en su regulación que revele la obligación de la Administración de la Junta de Andalucía de proceder al refuerzo que se aprecia como necesario ${ }^{70}$.

\section{IV.2. Las obligaciones de los Municipios Turísticos de Andalucía}

La declaración como MTA comporta una serie de obligaciones para los municipios. Así, se establece la de «llevar a cabo actuaciones dirigidas a potenciar y mejorar las actuaciones y servicios con incidencia en la actividad turística» (artículo 15.1 DMTA). Prevista ya en el artículo 15.1 del D/2002, ahora se suprime la mención de que esas actuaciones y servicios sean los mencionados entre los elementos de valoración ${ }^{71}$. Por otra parte, el apartado segundo del artículo 15 añade otras obligaciones que se imponen directamente, al margen de los convenios que se puedan suscribir y de índole muy diferente a las acciones que en 2006 debían formar parte del contenido necesario de los convenios ${ }^{72}$. Son las siguientes:

«a) Introducir mecanismos de participación ciudadana y de los agentes económicos y sociales en todos los procesos de planificación turística que se lleven a cabo. b) Integrar la conservación del patrimonio cultural y natural en la planificación turística, prestando especial atención al patrimonio intangible y a los valores, costumbres y tradiciones propias del municipio. c) Promover la accesibilidad universal de los recursos turísticos locales. d) Apostar por un turismo respetuoso con el entorno y sus habitantes, que tenga en cuenta la capacidad de carga del destino y tome conciencia de la limitación de los recursos naturales del territorio. e) Concienciar a la población local y a la población turística asistida de la importancia de una práctica turística responsable, promoviendo actividades igualitarias, educativas y de divulgación sobre el turismo y el desarrollo sostenible».

El nuevo conjunto de obligaciones revela una visión más avanzada del tratamiento del fenómeno turístico, confiriendo valor al patrimonio intangible del municipio, prestando mayor atención a la capacidad de carga del destino ${ }^{73} \mathrm{y}$ trayendo a primer plano lo que se ha denominado (ROMÁN MÁRQUEZ ${ }^{74}$ ) «la problemática

70 Como acabamos de ver, la obligación que establece el artículo 14.1 DMTA se ordena «compensar el mayor esfuerzo económico adicional que realiza el municipio». Por otra parte, el artículo 9.2 tampoco prevé que la propuesta de informe de la Secretaría General contemple ninguna mejora o refuerzo de las instalaciones o servicios autonómicos.

71 En todo caso, no resulta indiferente la trayectoria que siga el MTA respecto de las actuaciones y servicios que se incluyen entre los elementos de valoración, ya que el artículo 21.c) DMTA considera como causa de revocación de la declaración la «progresiva disminución de la calidad de los servicios municipales que se presten a la población turística asistida, para lo cual se atenderá preferentemente a los elementos de valoración previstos en el artículo 3». En la regulación anterior era causa de revocación la «[v]ariación sustancial de las circunstancias y servicios del artículo 3 del presente Decreto considerados al emitir la declaración de Municipio Turístico», apreciándose por consiguiente una mayor exigencia ahora en el mantenimiento de la calidad.

72 El artículo 15.2 del D/2002 (redacción de 2006) enumeraba las acciones del municipio que debían incluir los convenios.

73 Vid. FERREIRA FERNÁNDEZ y NOGUEIRA LÓPEZ (2001: 269 y ss.). Vid. también BENÍTEZ ROCHEL (2005), que concluye que, aunque «los problemas medioambientales de los municipios andaluces no están motivados -exclusivamente- por el turismo [...] a medida que se intensifica el carácter turístico de los municipios, crecen sus necesidades objetivas en materia medioambiental».

74 2008: 325 y ss. y 1201 
social» de los municipios turísticos. Asimismo, refleja la relevancia que adquiere en la nueva ordenación «el cómo» además de «el qué».

\section{IV.3. Los convenios de colaboración}

La posibilidad de suscribir convenios ${ }^{75}$ es uno de los elementos característicos del régimen jurídico de los municipios turísticos desde que la L99 previera la figura ${ }^{76}$.

El artículo 8 L99 vinculó los convenios con la compensación de «la mayor onerosidad en la prestación de los servicios». Sin embargo, y como ROMÁN MÁRQUEZ pusiera de manifiesto, su finalidad era más amplia, pues con ellos se perseguía "estimular el aumento de la "calidad integral" de los recursos ofertados por el municipio» ${ }^{77}$. Así se deduce de los diferentes acuerdos de declaración de MT, ninguno de los cuales reseña como finalidad esencial de los convenios que se suscriban la compensación por la mayor onerosidad de los servicios ${ }^{78}$, de modo que solo algunas de las líneas básicas de actuación de los convenios recogidas en los referidos acuerdos guardan alguna relación con la compensación aludida ${ }^{79}$. El análisis de los convenios publicados en el $B O J A^{80}$, así como los datos de que se disponen sobre su ejecución ${ }^{81}$, confirman lo expuesto.

75 En la solicitud de declaración de MTA ha de consignarse, en su caso, la voluntad de suscribir un convenio de colaboración (artículo 4.3 DMTA). En el acuerdo del Consejo de Gobierno que efectúe la declaración deben recogerse, si fuera a suscribirse el convenio, las líneas básicas de colaboración y la mención a las consejerías que lo suscribirán (artículo 12.1 DMTA). En la nueva regulación (artículo 18 DMTA), se prevé la posibilidad de que el MTA suscriba un convenio de colaboración con todas las consejerías que hayan manifestado su voluntad al efecto y hayan quedado determinadas en el acuerdo del Consejo de Gobierno, pudiendo posteriormente adherirse otras consejerías (bajo el régimen establecido en 2002, eran varios los convenios que podía celebrar cada municipio, aunque en las distintas declaraciones de MT que han tenido lugar solo se hace referencia a la suscripción de un convenio con la consejería competente en materia de turismo y a la eventual adhesión de otras consejerías); se mantiene la posibilidad de que puedan adherirse otras administraciones públicas y entidades públicas, aunque ya no se prevé, en cambio, la adhesión de entidades privadas, que sí consentía el artículo 13.1 del D/2002.

${ }^{76}$ Se han publicado en el BOJA los convenios suscritos con los municipios de Santiponce (BOJA 29, de 13 de febrero de 2006), Nerja (BOJA 30, de 14 de febrero de 2006), Roquetas de Mar (ibídem), Aracena (BOJA 31, de 12 de febrero de 2007), Cazorla (ibídem), Ronda (ibídem), Chiclana de la Frontera (BOJA 32, de 13 de febrero de 2007), Conil de la Frontera (ibídem), Tarifa (ibídem), Torremolinos (BOJA 33, de 15 de febrero de 2008), Fuengirola (ibídem), Rota (ibídem) y Chipiona (ibídem). Dado que Baza y Punta Umbría alcanzaron la condición de MT en 2017, es explicable la ausencia de convenio. Por otra parte, en el Parlamento de Andalucía se han reconocido las dificultades presupuestarias para concluir un convenio con Almuñécar (vid. el Boletín Oficial del Parlamento de Andalucía 336, IX Legislatura, de 18 de noviembre de 2013, pág. 40). Por lo que respecta a Benalmádena, y salvo error por mi parte, no se ha publicado ningún convenio en el BOJA; no obstante, en el Boletín Oficial del Parlamento de Andalucía 162, VIII Legislatura, de 26 de enero de 2009 , pág. 28, se proporciona información acerca de un convenio suscrito con vigencia 2004-2009 (vid. también la pág. 16 del Boletín 171, VIII Legislatura, de 6 de febrero de 2009). En relación con Almonte, y de nuevo salvo error por mi parte, el BOJA tampoco ha publicado ningún convenio; sin embargo, en el Boletín Oficial del Parlamento de Andalucía 269, VIII Legislatura, de 1 de julio de 2009, pág. 77, se consigna el inicio de los trámites para la firma del convenio; y en el Boletín 232, IX Legislatura, de 29 de mayo de 2013, pág. 24, se recoge lo siguiente: «dentro del "Convenio de Colaboración entre la Consejería y el Ayuntamiento de Almonte en ejecución de acuerdo de Consejo de Gobierno de declaración de Municipio Turístico", que refleja un compromiso de pago por importe de 235.486,69 euros». A través de los convenios, la consejería competente en materia de turismo ha aportado una financiación de 17.616.184,81 euros (Diario de Sesiones del Parlamento de Andalucía, Comisiones, núm. 118, X Legislatura, 10 de diciembre de 2015, pág. 8).

77 2008: 458.

78 Todos ellos se refieren al «aumento de la competitividad turística de los destinos compatible con la conservación y mejora de las características medioambientales de los mismos» y, adicionalmente en los acuerdos de declaración de MT de Aracena, Conil de la Frontera, Tarifa, Torremolinos, Chiclana de la Frontera, Chipiona y Fuengirola, a «la concreción de los compromisos del municipio en relación con aquellos servicios públicos de mayor relevancia y repercusión para el turismo», que obviamente no es lo mismo que compensar.

79 En los acuerdos de declaración de MT de Benalmádena, Santiponce, Ronda, Roquetas de Mar, Cazorla, Nerja y Almonte se incluyen como líneas básicas de actuación «[p]romover la calidad en la prestación de los servicios públicos municipales al conjunto de sus usuarios» y "[p]reservar y mejorar las infraestructuras y equipamientos urbanos». En los acuerdos de declaración de MT de Aracena, Conil de la Frontera, Tarifa, Torremolinos, Chiclana de la Frontera, Chipiona, Fuengirola, Rota, Almuñécar, Baeza, y Punta Umbría se incluyen como líneas básicas de actuación «[m]ejora de la calidad en la prestación de los servicios públicos municipales al conjunto de los usuarios» y «[p]reservación del patrimonio cultural, urbano y medioambiental».

${ }^{80}$ En ellos se recoge como finalidad el establecer un marco de colaboración para la calidad de los servicios mediante una serie de acciones que, con ligeras variantes entre unos y otros convenios, son las siguientes: 1. acondicionamiento, rehabilitación y valorización de los recursos y enclaves turísticos; 2. planificación de los recursos y enclaves turísticos del municipio e integración en tomo a sus grandes referentes culturales; 3 . preservación y mejora de las infraestructuras de los principales recursos turísticos; 4 . desarrollo de la actividad turística compatible con el respeto a los valores naturales; 5 . acondicionamiento y cualificación del espacio turístico (equipamiento, señalización, etc.); 6 . la promoción de los servicios públicos municipales al conjunto de los usuarios turísticos; 7 . favorecer la implantación de servicios turísticos y de atención al turista de calidad; 8. mayor diversificación de la oferta de actividades; 9 . impulsar la ejecución de planes de recualificación [en concreto, el Plan Recualificación de la Costa del Sol Occidental (Qualifica) en los convenios suscritos con Torremolinos y con Fuengirola].

81 Vid. el Boletín Oficial del Parlamento de Andalucía 162, VIII Legislatura, de 26 de enero de 2009, pág. 28 y ss., en las que se detalla el destino de la aportación económica de la Administración andaluza comprometida en cada convenio. La misma información se encuentra en el Boletín 171, VIII Legislatura, de 6 de febrero de 2009, pág. 16 y ss. 
Actualmente, el artículo 20.4 LTA señala que el objeto de los convenios es «compensar el incremento en la demanda de la prestación de los servicios», aunque del artículo 18.2 DMTA se desprende, hoy también, una mayor amplitud de fines, añadiéndose a la calidad la pretensión de actuar sobre factores estructurales.

En efecto, el precepto dispone la adopción de medidas para alcanzar, «al menos», los fines que se reseñan, que son los siguientes:

«a) Mejorar los servicios públicos específicos de competencia municipal que tengan una especial relevancia para la actividad turística. b) Proteger los valores tradicionales y culturales de la población autóctona. c) Salvaguardar el medio ambiente y los valores ecológicos de Andalucía. d) Preservar los bienes públicos y privados relacionados con el turismo municipal. e) Aumentar, diversificar y mejorar la oferta turística complementaria, así como crear nuevos productos, velando por la inclusión de medidas que favorezcan la desestacionalización y la mejora de la calidad del empleo. f) Sensibilizar e implicar a la población y a los agentes locales en una cultura igualitaria y de calidad de vida. g) Evitar la saturación turística del destino, atendiendo a su capacidad de carga».

Esta enumeración coincide con la que contenía el artículo 13.2 del D/2002, con las siguientes salvedades: 1) en lugar de mencionar «las condiciones de salubridad pública, protección civil y seguridad en lugares públicos» (apartado a), la referencia tiene lugar a «servicios públicos específicos de competencia municipal que tengan una especial relevancia para la actividad turística», lo que revela un paso más en aras de la calidad integral aludida; 2) además de la cultura de calidad de vida, se menciona la cultura igualitaria; 3) se introduce la alusión a «medidas que favorezcan la desestacionalización y la mejora de la calidad del empleo»; 4) y se añade como nuevo fin el de «evitar la saturación turística del destino, atendiendo a su capacidad de carga». Las dos últimas novedades revelan la pretensión de actuar sobre factores estructurales y enlazan, como también sucede con la alusión a la cultura igualitaria y en general con todos los fines enunciados, con las obligaciones que el artículo 15.1 y 2 impone al municipio. En todo caso, se advierte que el DMTA concibe el convenio más como un instrumento para incrementar el atractivo turístico del municipio y la consecución de nuevas cotas de calidad, a la par que como una herramienta estratégica para incidir sobre factores estructurales, que como una vía para compensar las dificultades financieras que plantea la desproporción entre la población de derecho y los visitantes que recibe el municipio; y ello aun cuando se esfuerce en enfatizar que «los convenios tendrán por objeto compensar el incremento de la demanda de la prestación de los servicios» (artículo 18.2).

A diferencia de lo establecido en el artículo 15.2 del D/2002, conforme a la redacción dada en 2006, no se enumeran acciones concretas de los municipios que deban figurar en los convenios ${ }^{82}$. Ha de tenerse en cuenta que la regulación anterior propició que el convenio comportara una doble carga para el MT: una, la de ejecutar los proyectos concretos que se financiaban a través del convenio ${ }^{83} ; \mathrm{y}$ otra, la de llevar a cabo las actuaciones que se establecían en el anexo III del mismo ${ }^{84}$, que se correspondían con todas o algunas de las previstas en el artículo 15.2 del D/2002 tras su reforma en $2006^{85}$. Por ello, si la suscripción del convenio no lleva aparejadas ahora otras obligaciones distintas de las que se vayan a financiar a través del mismo, el nuevo enfoque debe ser valorado positivamente ${ }^{86}$.

82 El artículo 13.2 del D/2002, en su versión original, no detallaba medidas, sino que establecía los fines que como mínimo se debían alcanzar con las medidas que se adoptaran. En todo caso, hay que tener en cuenta que la mayoría de las acciones que sí se enumeraban en la versión de 2006: o bien están contempladas en el DMTA como elementos de valoración o como obligaciones de los MTA; o bien se corresponden con los fines que deben alcanzarse con los convenios; o bien se refieren a servicios con los que cuentan de ordinario los municipios.

83 Todos los convenios suscritos reservaron a la Comisión de Seguimiento del convenio la determinación de las actuaciones que se financiarían.

84 Todos los convenios han mantenido una misma estructura. Los anexos III recogían las actuaciones del municipio en cuestión.

85 Incluso en los convenios suscritos con Santiponce, Nerja y Roquetas de Mar, anteriores a la reforma del D/2002 (las resoluciones que les dan publicidad son todas de 30 de enero de 2006), pero que se gestaron al tiempo de la tramitación de aquella.

86 Tomando como ejemplo el convenio suscrito con Chipiona, se puede apreciar mejor lo expuesto. Así, constan en el anexo III distintas actuaciones que debía realizar el municipio relativas a servicios para turistas y visitantes, señalización turística, accesibilidad a los recursos turísticos, promoción turística, creación de productos turísticos, protección del medio urbano y natural, playas y formación. Sin embargo, los 772.861,37 euros aportados por la Consejería de Turismo, Comercio y Deporte tenían como destino el Corredor Verde Litoral "Costa Ballena-Chipiona», según se lee en la pág. 29 del Boletín Oficial del Parlamento de Andalucía 162, VIII Legislatura, de 26 de enero de 2009, así como en la pág. 17 del Boletín 171, VIII Legislatura, de 6 de febrero de 2009. 


\section{IV.4. Otras formas de colaboración interadministrativa}

El artículo 13.1 DMTA alude a «otras formas de colaboración interadministrativa», aunque no queda claro si éstas son, sencillamente, las que entrañan las obligaciones de la Administración de la Junta de Andalucía recogidas en el artículo 14.

La práctica posterior, sin embargo, ha evidenciado que efectivamente hay otras formas de colaboración. En este sentido, mediante Orden de 27 de julio de 2017 se han aprobado las bases reguladoras para la concesión de subvenciones, en régimen de concurrencia no competitiva, a los municipios turísticos de Andalucía ${ }^{87}$, cuyo preámbulo establece expresamente su incardinación en «esas otras posibles formas de colaboración interadministrativa» ${ }^{88}$. Estas bases tienen vigencia indefinida y está prevista la convocatoria anual de las subvenciones (disposición adicional única de la Orden).

La aprobación de estas bases reguladoras y manifestaciones efectuadas en el Parlamento de Andalucía, junto con la circunstancia de que los convenios que se han firmado con los municipios turísticos (MTs en lo sucesivo) no se han renovado, sugieren que la administración andaluza parece haber dejado en segundo plano la política de financiar los MTs a través de convenios y optado por esta línea de convocatoria directa de subvenciones en régimen de concurrencia no competitiva ${ }^{89}$.

Porque no ha transcurrido el tiempo suficiente al efecto, no es factible realizar una valoración rigurosa de esta posible nueva preferencia ni, tampoco, inferir con certeza la política que, en términos más generales, haya trazado la administración autonómica, aunque sí cabe apuntar tres cuestiones. La primera, que quizás se haya considerado la oportunidad de reservar la suscripción de convenios para cuando se declaren nuevos MTAs, encauzándose la financiación de los ya existentes a través de las subvenciones que se convoquen al amparo de la Orden de 27 de julio de $2017^{90}$. La segunda, que la finalidad de las ayudas no es compensar el mayor esfuerzo financiero que supone la prestación de servicios a la población turística asistida, ya que directamente se ordenan a sufragar nuevas actuaciones y proyectos relacionados con los espacios y recursos turísticos ${ }^{91}$. La tercera, que se introduce una referencia cierta, igual para todos los municipios ${ }^{92}$, en orden a la determinación de la cuantía de la subvención, que es la participación de cada municipio turístico, en el ejercicio económico anterior al de la convocatoria, en el fondo de participación de las entidades locales en los tributos de la Comunidad Autónoma de Andalucía (PATRICA) ${ }^{93}$.

${ }_{87}$ BOJA 147, de 2 de agosto. La primera convocatoria de subvenciones se ha realizado por Orden de 26 de septiembre de 2017 (BOJA 191, de 4 de octubre).

${ }_{88}$ Con todo, la Orden también razona que las bases reguladoras son una de las medidas que tienen cabida en el Plan General de Turismo Sostenible de Andalucía Horizonte 2020, aprobado por Decreto 37/2006, de 9 de febrero. Por consiguiente, puede entenderse que con ellas se da cumplimiento a la obligación impuesta en el artículo 14.1 DMTA, considerando que dicho plan puede caracterizarse como un plan económico.

89 Vid. las manifestaciones del Consejero de Turismo y Deporte en la Comisión de Turismo y Deporte del Parlamento de Andalucía, sesión de 19 de octubre d 2017, recogidas en el Diario de Sesiones del Parlamento de Andalucía. Comisiones. Núm. 433. X Legislatura. 19 de octubre de 2017; vid. también las realizadas el 21 de septiembre de 2017, (Diario de Sesiones del Parlamento de Andalucía, Comisiones, núm. 407, X Legislatura, 21 de septiembre de 2017, pág. 14)

90 Otra posibilidad es que los convenios se reserven «para atender demandas sectoriales concretas», como afirmó el Consejero de Turismo y Deporte en la Comisión de Turismo y Deporte del Parlamento de Andalucía en sesión celebrada el 10 de diciembre de 2015 (vid. Diario de Sesiones del Parlamento de Andalucía, Comisiones, núm. 118, X Legislatura, 10 de diciembre de 2015, págs. 8 y 9). Ello puede explicar que en el DMTA, a diferencia de la regulación establecida en 2006 , no se detallen las acciones que deben figurar en los convenios.

91 Vid. los conceptos subvencionables en el apartado 2 del cuadro resumen de las bases reguladoras.

92 ROMÁN MÁRQUEZ (2008: 1230) se pronunció a favor de que el mecanismo de financiación fuera idéntico para todos los municipios.

${ }_{93}$ Habría sido más oportuno que las bases reguladoras hubieran precisado la cuantía anual de la subvención estableciendo un porcentaje fijo referido a la participación en el fondo o, al menos, el porcentaje mínimo referido a dicha participación. Sin embargo, se han limitado a señalar el máximo posible (un 10\% de la participación de cada municipio turístico), dejando que el porcentaje concreto se determine en cada convocatoria (vid. el apartado 5 del cuadro resumen de las bases reguladoras). La convocatoria efectuada por la Orden de 26 de septiembre de 2017, ya citada, llega al máximo del porcentaje, de manera que «[l] os importes máximos de las subvenciones que correspondan a las entidades beneficiarias resultarán de aplicar un $10 \%$ sobre la participación de cada una de ellas, en el ejercicio 2016, en el Fondo de Participación de las entidades locales en los tributos de la Comunidad Autónoma de Andalucía (PATRICA)»; por otra parte, especifica que se podrán adquirir compromisos de carácter plurianual. En el Parlamento de Andalucía se ha anunciado que la convocatoria de 2018 cuenta con el mismo presupuesto que en 2017, por lo que cabe deducir que el porcentaje previsto es el máximo posible, esto es, el $10 \%$ de la participación en el fondo (vid. el Diario de Sesiones del Parlamento de Andalucía, Comisiones, núm. 433, X Legislatura, 19 de octubre de 2017, pág. 74). 


\section{CONCLUSIONES}

Primera: la calidad impregna en mayor medida la nueva regulación Así lo evidencia el que se haya incrementado llamativamente el número de los elementos de valoración, que éstos hayan pasado a conformarse realmente como requisitos, la propia índole de los nuevos elementos que se han introducido y la circunstancia de que algunos de ellos estaban previstos como acciones que debían realizar los municipios una vez alcanzada la condición de $\mathrm{MT}^{94}$. También lo demuestra el que se haya dotado de significado al requisito de la oferta turística anudándolo a factores que son indicativos de calidad. Es igualmente muestra de ello la ampliación de los fines de los convenios, en concreto, la pretensión de mejorar todos «los servicios públicos específicos de competencia municipal que tengan una especial relevancia para la actividad turística» [artículo 18.2.a) DMTA] ${ }^{95}$. Y, cómo no, la exigencia de un plan municipal de calidad turística en lugar de «un plan turístico municipal o instrumento de planificación turística similar» (artículo 3.4 del D/2002) ${ }^{96}$; plan municipal de calidad turística que, además, se configura como un requisito de ineludible cumplimiento y no como un elemento de valoración, que es la caracterización que tenía en 2002. Por último, se ha introducido como nueva causa de revocación de la declaración de MTA la «progresiva disminución de la calidad de los servicios municipales que se presten a la población turística asistida» [artículo 21.b) DMTA] ${ }^{97}$.

Segunda: se acentúa la consideración de la declaración de MTA como un punto de partida y no una meta de llegada ${ }^{98}$. Entraña la obligación de potenciar y mejorar las actuaciones y servicios con incidencia en la actividad turística, sean o no de los seleccionados como elementos de valoración; e implica un compromiso añadido en cuanto a los «modos de hacer». Y todo ello en un esfuerzo continuado en pos de la calidad que, como objetivo último, preside la regulación ${ }^{99}$.

Tercera: se confirma que la motivación originaria de la figura del MT tiene en el Derecho de Andalucía una relevancia absolutamente residual, pues la financiación que se allega por la vía de los convenios y de las subvenciones amparadas en la Orden de 27 de julio de 2017 persigue aportar ingresos para nuevas actuaciones y proyectos turísticos. No se pretende compensar los gastos que genera la afluencia turística sino mantener y elevar el atractivo turístico del municipio. En teoría, los recursos adicionales que son necesarios por la desproporción entre la población de derecho y la población turística vendrían de la mano de la acción de fomento derivada de los planes económicos de la administración andaluza, siempre que, claro está, «resulte compatible con los objetivos de los mismos y en su caso, con el carácter finalista de su financiación» (artículo 14.1 DMTA) ${ }^{100}$. El régimen de los MTAs, pues, se orienta, sencillamente, a fortalecer el sector económico del turismo, considerado como «elemento económico estratégico de Andalucía» (artículo 37.1.14 del Estatuto de Autonomía).

94 Recordemos que, inicialmente, el artículo 15 del D/2002 no impuso ninguna obligación sustantiva concreta a los MTs, prescribiendo solo el deber de «llevar a cabo actuaciones dirigidas a mejorar los servicios públicos a que se refiere el artículo 3 , pudiendo ser objeto de los convenios, entre otras, el establecimiento de medidas para ejecutar programas que potencien y promocionen los recursos turísticos». En la reforma de 2006 se asume un planteamiento distinto que explica el preámbulo del D/2006: se «pretende, además, concretar las obligaciones de los municipios respecto de aquellos servicios públicos que por su relevancia y repercusión en el turismo deben suponer un especial compromiso por parte de los municipios declarados, debiéndose incluir necesariamente como contenido de los convenios que celebren con la Administración turística, de esta forma, la declaración de Municipio Turístico no se concibe tanto como un reconocimiento sino como un compromiso por parte de la entidad local en potenciar y mejorar sus servicios públicos, especialmente aquellos que inciden directamente en la percepción del turista». En consecuencia, el artículo 15.2 pasa a enumerar acciones concretas que deben realizar los municipios. En 2017 se da un paso más: algunas de las acciones que los MTs debían realizar se configuran como elementos de valoración, de manera que ya no suponen una meta sino que son un presupuesto para alcanzar el reconocimiento como MTA.

95 En 2002 se perseguía la mejora de «las condiciones de salubridad pública, protección civil y seguridad en lugares públicos» [artículo 13.2.a) del D/2002].

96 En la reforma de 2006 se prescindió de la mención al «instrumento de planificación turística similar» [artículo 3.c)].

97 El artículo 17.1.a) del D/2002 se refería a la variación sustancial de las circunstancias y servicios contemplados como elementos de valoración.

98 Certeramente advirtió ROMÁN MÁRQUEZ (2008: 426) que el régimen del MT (y en particular los elementos de valoración) se endereza a seleccionar a aquellos municipios atentos al fenómeno turístico, desde la premisa de que «el legislador andaluz rechaza asimismo la idea de concluir convenios de colaboración con municipios que ni se han preocupado nunca del turismo como deberían, ni lo harán probablemente aunque sean declarados Municipios Turísticos» (las cursivas en el original).

99 Vid. en sentido parecido ROMÁN MÁRQUEZ, 2008: 472.

100 Como señalara ROMÁN MÁRQUEZ (2008: 1204), «[t]odo el edificio jurídico creado en torno al Municipio Turístico tiene como objetivo esencial la consecución de dos principios básicos: la calidad integral de la oferta turística local y su sostenibilidad económica, social y ambiental». La sostenibilidad económica, en mi opinión, se predica en esta regulación de la actividad turística del municipio y no del conjunto de servicios y actuaciones que, siendo precisos para la población de derecho, entrañan un coste adicional debido a la magnitud de la suma de esta población y de los visitantes. 


\section{REFERENCIAS BIBLIOGRÁFICAS}

BERMEJO VERA, J. (2001): "Régimen jurídico de los municipios turísticos”, Documentación Administrativa, 259-260: 213-250.

BLANQUER CRIADO, D. (2004): “La calidad ambiental de los destinos turísticos urbanos”, en BLANQUER, D., ed.: Turismo cultural y urbano. $6 .^{\circ}$ Congreso de Turismo Universidad y Empresa: 527-580. Valencia: Tirant Lo Blanch.

BENÍTEZ ROCHEL, J. J. (2005): "Impacto medioambiental en los municipios turísticos de Andalucía", en AURIOLES MARTíN, A., ed.: IV, V y VI Jornadas de Derecho Turístico en Andalucía: 337-354. Sevilla: Consejería de Turismo, Comercio y Deporte.

BOUAZZA ARIÑO, O. (2012): "Regímenes locales especiales en materia de turismo", Anuario aragonés del gobierno local, 4: 257-292.

CARBONELL PORRAS, E. (2007): “Artículo 30", en REBOLLO PUIG, M., ed.: Comentarios a la Ley Reguladora de las Bases del Régimen Local, tomos: 773-790. Valencia: Tirant Lo Blanch.

CALONGE VELÁZQUEZ, A. y VILLAREJO GALENDE, H. "Municipios turísticos y horarios comerciales", en BLANQUER, D., ed.: III Congreso Universidad y Empresa. Municipios turísticos. Tributación y contratación empresarial. Formación y gestión del capital humano: 331-358. Valencia: Tirant Lo Blanch.

CORNO CAPARRÓS, L. (1984): "El estatuto legal del municipio turístico: apuntes para una propuesta", Revista Española de Derecho Administrativo, 42: 423-434.

FERNÁNDEZ RAMOS, S. (2003): "El régimen jurídico del municipio turístico en Andalucía. El Derecho a la carta", Revista Andaluza de Administración Pública, 52: 51-85. Publicado también en (2005) AURIOLES MARTíN, A., ed.: IV, V y VI Jornadas de Derecho Turístico en Andalucía: 379-408. Sevilla: Consejería de Turismo, Comercio y Deporte.

- (2017): "Las administraciones turísticas andaluzas", en FERNÁNDEZ RAMOS, S. y PÉREZ MONGUIÓ, J. M., eds.: Estudios sobre el Derecho del Turismo de Andalucía: 19-101. Sevilla: Instituto Andaluz de Administración Pública.

FERREIRA FERNÁNDEZ, A. X. y NOGUEIRA LÓPEZ, A. (2001): "Aspectos jurídicos de un desarrollo turístico sostenible", Documentación Administrativa, 259-260: 251-286. Publicado también (2002): en BLANQUER, D., ed.: IV Congreso de Turismo Universidad y Empresa. La diversificación y la desestacionalización del sector turístico: 483-516. Valencia: Tirant Lo Blanch.

GALLARDO CASTILLO, M. J. (1996): "La ordenación Jurídico-Administrativa del Turismo", Revista Andaluza de Administración Pública, 25: 37-58.

- (2001): "La distribución constitucional de competencias en materia de turismo y su tratamiento en las Leyes Autonómicas: su promoción y ordenación", Documentación Administrativa, 259-260: 71-94.

GIL CASIÓN, I. (2011): "Problemas actuales en el ámbito de los municipios turísticos", Revista Andaluza de Derecho del Turismo, 5: 156-190.

GUILLÉN GALINDO, M. A. (1999): "La distribución de competencias en materia turística entre el Estado, las Comunidades Autónomas y la Entidades Locales. Especial referencia a la Comunidad Valenciana”, en BLANQUER, D., ed.: Turismo. Organización administrativa, calidad de servicios y competitividad empresarial. I Congreso Universitario de Turismo: 37-60. Valencia: Tirant Lo Blanch.

ILDEFONSO HUERTAS, R. M. (2003): "Las políticas de turismo en la Comunidad Autónoma de Andalucía", Revista Andaluza de Administración Pública, extraordinario 2, 2003: 179-204.

LASARTE ÁLVAREZ, J. y ADAME MARTÍN, F. D. (2005): "Consecuencias de la calificación como municipio turístico en relación con los gastos e ingresos públicos", en AURIOLES MARTíN, A., ed.: IV, V y VI Jornadas de Derecho Turístico en Andalucía: 37-85. Sevilla: Consejería de Turismo, Comercio y Deporte.

LLAGAS GELO, F. (2017): "Intervención administrativa por razón de la actividad turística: de los centros y zonas de interés turístico al modelo del «municipio turístico»", Revista Internacional de Derecho del Turismo, 1: 117-136.

MELGOSA ARCOS, F. J. (2011): “Administraciones locales y turismo: el municipio turístico", en BALLESTEROS ARRIBAS, S., ed.: Administración local. Estudios en homenaje a ÁNGEL BALLESTEROS FERNÁNDEZ: 1.1671.207. Las Rozas: El Consultor de los Ayuntamientos y Juzgados (Grupo Wolters Kluwer).

RAZQUÍN LIZÁRRAGA, M. M. (2000): “Organización local del turismo", en BLANQUER, D., ed.: III Congreso Universidad y Empresa. Municipios turísticos. Tributación y contratación empresarial. Formación y gestión del capital humano: 39-68. Valencia: Tirant Lo Blanch.

RIVERO YSERN, J. L. (2000): "Notas sobre el municipio turístico en la Ley 12/99 de 15 de diciembre, Ley del Turismo de Andalucía", en AURIOLES MARTíN, A., ed.: Derecho y Turismo. III Jornadas de Derecho Turístico. Málaga 2000: 85-90. Sevilla: Consejería de Turismo y Deporte.

- (2001): "Notas sobre la Ley 12/1999 de 15 de diciembre, reguladora del turismo en Andalucía", Documentación Administrativa, 259-260: 199-212.

- (2005): "Municipio turístico y régimen local", en AURIOLES MARTÍN, A., ed.: IV, V y VI Jornadas de Derecho Turístico en Andalucía: 479-484. Sevilla: Consejería de Turismo, Comercio y Deporte.

- (2008): "Entidades Locales y turismo. Especial referencia al municipio turísitico", en FERNÁNDEZ RAMOS, S., ed.: Estudios sobre el Derecho Andaluz del Turismo: 119-142. Sevilla: Consejería de Turismo, Comercio y Deporte. 
REALA. Nueva Época - N. ${ }^{9}$, Abril 2018 - ISSN: 1989-8975 - DOI: 10.24965/reala.v0i9.10520 - [Págs. 22-40]

El municipio turístico de Andalucía: claves sustantivas de su nueva regulación

María del Carmen Núñez Lozano

ROMÁN MÁRQUEZ, A. (2008): El municipio turístico. Régimen jurídico y algunas propuestas para su mejora. Tesis Doctoral, Universidad de Granada. Disponible en web: https://hera.ugr.es/tesisugr/18608784.pdf.

SANZ DOMÍNGUEZ, C. (2003): "La calidad del turismo en la legislación turística: en particular el caso de Andalucía", en BLANQUER, D., ed.: V Congreso de Turismo Universidad y Empresa. La calidad integral del turismo: 341-360. Valencia: Tirant Lo Blanch.

SUAY RINCÓN, J. y RODRÍGUEZ GONZÁLEZ, M. P. (1999): "Las competencias turísticas de los municipios. En particular, la categoría de los Municipios turísticos", en BLANQUER, D., ed.: Turismo. Organización administrativa, calidad de servicios y competitividad empresarial. I Congreso Universitario de Turismo: 61-86. Valencia: Tirant Lo Blanch.

TUDELA ARANDA, J. (1996): "Hacia un nuevo régimen jurídico del turismo: la reciente legislación autonómica", Revista Vasca de Administración Pública, 45-I: 291-350.

- (2001): "La ley y el reglamento en el Derecho del turismo", Documentación Administrativa, 259-260: 95-142. 